ORIGINAL ARTICLE

\title{
Fatal pulmonary embolism in hospitalised patients: a necropsy review
}

\author{
R Alikhan, F Peters, R Wilmott, A T Cohen
}

J Clin Pathol 2004;57:1254-1257. doi: 10.1136/jcp.2003.013581

See end of article for authors' affiliations .....................

Correspondence to: Miss R Wilmott, Academic Department of Surgery, Guy's, King's, and St Thomas's School of Medicine, Bessemer Road, London SE5 9PJ, UK; rosalind.wilmott@kcl.ac.uk

Accepted for publication 16 March 2004
Aims: To carry out a retrospective review of all postmortem reports during the period 1991 to 2000 at King's College Hospital, London, as an extension of a previous analysis performed for the period 1965 to 1990.

Methods: The number of deaths resulting from necropsy confirmed fatal pulmonary embolism in hospitalised patients was determined, and a limited analysis of the clinical characteristics of those patients who died was performed.

Results: During the 10 year period, 16104 deaths occurred and 6833 (42.4\%) necropsies were performed. The outcome measure, fatal pulmonary embolism, was recorded as cause of death in 265 cases (3.9\% of all necropsies; $5.2 \%$ of adult cases). No deaths from pulmonary embolism occurred in patients under 18 years of age; $80.0 \%$ occurred in patients older than 60 years. Of the fatal emboli, 214 of $265(80.8 \%)$ occurred in patients who had not undergone recent surgery. Of these patients, 110 $(51.4 \%)$ had suffered an acute medical illness in the six weeks before death, most often an acute infectious episode (26 cases).

Conclusions: Thromboembolic events remain a relatively common cause of death in hospitalised patients and appear to occur more frequently in non-surgical than in surgical patients.
V enous thromboembolic disease (VTE), manifesting primarily as deep vein thrombosis and pulmonary embolism (PE), is recognised as a substantial health problem. ${ }^{12}$ The importance of VTE primarily relates to the risk of death from $\mathrm{PE}$, but the acute and chronic consequences of VTE are also of concern. ${ }^{3}$ Estimates of the prevalence of PE in patients recognised to be at risk of VTE have been derived from randomised clinical trials, ${ }^{12}$ and prospective population based analyses have provided some insight into the risk to the population as a whole. ${ }^{4}$ However, there remains a paucity of data in the literature describing the prevalence of $\mathrm{PE}$ or the clinical characteristics of hospitalised patients suffering fatal VTE events.

Hospitalisation is a common and important factor in patients presenting with VTE. A recent population based study that characterised the relative impact of risk factors for DVT and PE has shown that hospitalisation for surgery and for medical illness accounts for similar proportions of VTE episodes. ${ }^{5}$ This reflects a growing awareness throughout the 1990s that general medical patients and patients with cancer, rather than surgical patients who traditionally have been regarded as the at risk population, are also exposed to a risk of VTE. ${ }^{67}$ Indeed, in some studies the highest frequency of fatal PE has been described in non-surgical populations. ${ }^{8}$

"Hospitalisation is a common and important factor in patients presenting with venous thromboembolic disease"

Our present study is a continuation of a previous analysis at King's College Hospital, London, UK. ${ }^{9}$ At that time, the number of surgical patients dying from PE seemed to be reducing, a fact attributed to improvements in surgical and anaesthetic care and to the introduction of post surgical thromboprophylaxis in the health district. We undertook to continue the postmortem series over the next 10 year period (1991-2000) to determine how many deaths were caused by fatal PE and to examine, in a limited fashion, the characteristics of those patients dying from these fatal embolic events.

\section{MATERIALS AND METHODS}

Reports of every postmortem examination performed on inpatients at King's College Hospital, London, UK were obtained after a retrospective review for the period 1 January 1991 to 31 December 2000. Cases for inclusion were identified and data were derived from manually examining copies of the postmortem reports, as described previously, ${ }^{9}$ with the exception that a modified data abstraction form was developed and used. The data form recorded the patient sex, age, race, height, weight, and surgical status. In addition, evidence of DVT, myocardial infarction (MI), stroke, chronic obstructive pulmonary disease, cardiac failure, infection, or cancer was recorded from the postmortem report. Cases of fatal PE were classified as occurring in either surgical (if death occurred within eight weeks of surgery) or nonsurgical patients. This information was then entered into a computer database.

PE was recorded as the cause of death only when the necropsy stated that embolism was the main or contributing cause of death and identified emboli present either in the main pulmonary trunk or in the proximal right or left pulmonary arteries formed from the bifurcation of the main trunk. Emboli found in the distal pulmonary arteries after further division of the right and left pulmonary arteries were not included. Emboli derived from bone marrow, fat, tumour, or amniotic fluid were also excluded from the analysis.

The collection of PE data was part of an ongoing internal audit, and thus ethical approval was not required. The identity of the dead patients was protected by the use of code numbers on the data forms.

Abbreviations: $\mathrm{MI}$, myocardial infarction; NCEPOD, National Confidential Enquiry into Perioperative Deaths; PE, pulmonary embolism; VTE, venous thromboembolic disease 
Table 1 Deaths and necropsies at King's College Hospital, London, UK (1991-2000)

\begin{tabular}{lllllll}
\hline & & \multicolumn{2}{l}{$<\mathbf{1 8}$ years } & & $>\mathbf{1 8}$ years \\
Year & Death & $\begin{array}{l}\text { Death } \\
(\mathbf{n})\end{array}$ & $\begin{array}{l}\text { Necropsy } \\
\mathbf{n}(\%)\end{array}$ & & $\begin{array}{l}\text { Death } \\
(\mathbf{n})\end{array}$ & $\begin{array}{l}\text { Necropsy } \\
\mathbf{n}(\%)\end{array}$ \\
\hline 1991 & 1327 & 190 & $158(83)$ & & 1137 & $458(40)$ \\
1992 & 1450 & 240 & $185(77)$ & & 1210 & $502(41)$ \\
1993 & 1498 & 219 & $155(71)$ & & 1279 & $518(41)$ \\
1994 & 1436 & 275 & $219(80)$ & & 1161 & $512(44)$ \\
1995 & 1755 & 308 & $250(81)$ & & 1447 & $624(43)$ \\
1996 & 1802 & 266 & $184(69)$ & & 1536 & $634(41)$ \\
1997 & 1728 & 266 & $164(62)$ & & 1462 & $533(36)$ \\
1998 & 1705 & 240 & $120(50)$ & & 1465 & $466(32)$ \\
1999 & 1721 & 227 & $122(54)$ & & 1494 & $479(32)$ \\
2000 & 1682 & 213 & $169(79)$ & & 1469 & $381(26)$ \\
Total & 16104 & 2444 & $1726(71)$ & 13660 & $5107(37)$ \\
\hline
\end{tabular}

\section{RESULTS}

\section{Death and fatal pulmonary embolism}

There were 16104 patient deaths at King's College Hospital, London, UK, in the period 1991 to 2000. Death occurred in 13660 adult patients (patients aged more than 18 years) and 2444 children (patients aged less than 18 years). In total, 6833 necropsies were performed (42.4\% of cases), in 1726 children (70.6\% of deaths) and 5107 adults (37.4\% of deaths) (table 1).

PE was regarded as the primary cause of death in 265 cases in which a necropsy was performed $(3.9 \%$ of all necropsies; $5.2 \%$ of adult cases): in 51 surgical patients (19.2\%) and 214 non-surgical patients $(80.8 \%$ ) (table 2$)$. There were no deaths from $\mathrm{PE}$ in patients under the age of 18 years. Sixteen deaths occurred in patients between the ages of 18 and 40 years $(6.0 \%) ; 212$ patients $(80.0 \%)$ were greater than 60 years of age at the time of fatal PE (fig 1). The mean age (SD) of patients dying from PE was 72 (14.6) years. Fatal PE occurred more commonly in women $(155$ of $265 ; 58.5 \%)$ than in men (110 of $265 ; 41.5 \%)$.

The postmortem rate in the adult population over the 10 year period (1991-2000) was $37.4 \%$ of deaths (table 1$)$. The rate of necropsy in the adult population fell substantially

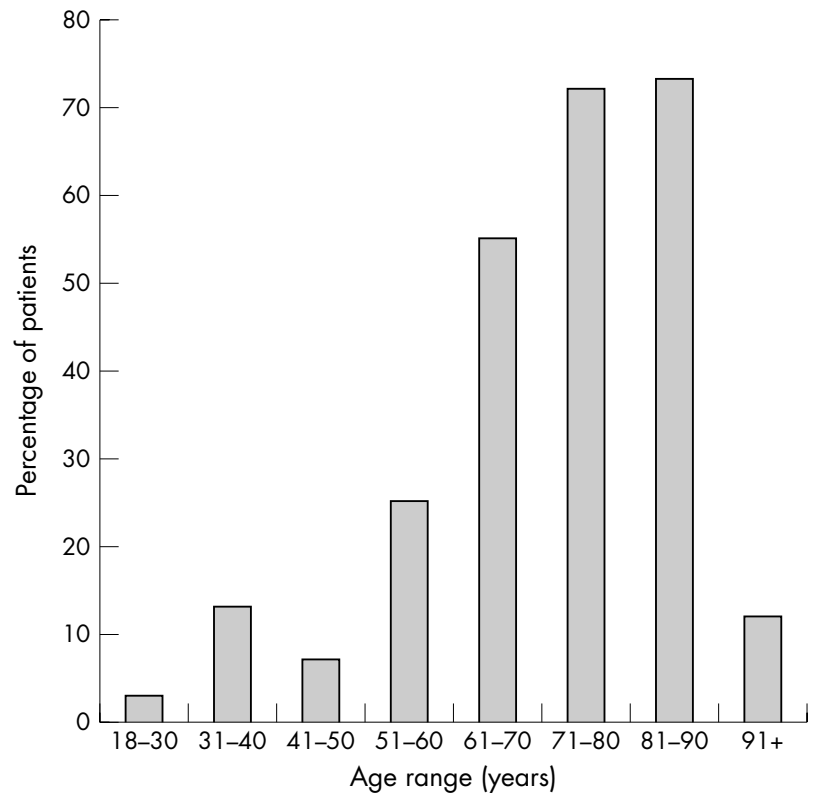

Figure 1 Age distribution of necropsy confirmed fatal pulmonary embolism.
Table 3 Necropsy rate and fatal pulmonary embolism 1966-2000

\begin{tabular}{lll}
\hline Year & $\begin{array}{l}\text { Necropsy } \\
\text { n }(\%)^{*}\end{array}$ & $\begin{array}{l}\text { Fatal PE } \\
\mathbf{n}(\%) t\end{array}$ \\
\hline $1966-1970$ & $3167(71 \%)$ & $192(6.1 \%)$ \\
$1971-1975$ & $3523(53 \%)$ & $187(5.3 \%)$ \\
$1976-1980$ & $2660(41 \%)$ & $120(4.5 \%)$ \\
$1981-1985$ & $2354(35 \%)$ & $54(2.3 \%)$ \\
$1986-1990$ & $2963(46 \%)$ & $62(2.1 \%)$ \\
$1991-1995$ & $3581(48 \%)$ & $139(3.9 \%)$ \\
$1996-2000$ & $3252(38 \%)$ & $126(3.9 \%)$ \\
\hline
\end{tabular}

${ }^{*} \mathrm{n}$, number of necropsies; \%, percentage of deaths. $t \mathrm{n}$, cases of fatal pulmonary embolism; \%, percentage of necropsies undertaken. $\mathrm{PE}$, pulmonary embolism.

during the last five year period of our study (1996-2000), from $41.9 \%$ to $33.6 \%$ (table 3 ).

\section{Death and medical illness}

Most deaths from PE (214 of 265) occurred in non-surgical patients (table 2); 110 occurred in patients who had unequivocally suffered a defined acute medical illness within six weeks of death, most often acute infection (26 of 110; $23.6 \%$ cases) and cancer ( 24 of $110 ; 21.8 \%$ ) (table 4 ).

\section{DISCUSSION}

Death from PE was a common finding in our analysis, accounting for $5.2 \%$ of adult necropsies at King's College Hospital, London, UK, in the 10 year period from 1991 to 2000. In the analysis of the adult population who underwent

Table 2 Fatal pulmonary embolism and reason for hospitalisation (1991-2000)

\begin{tabular}{llll}
\hline Year & $\begin{array}{l}\text { Surgical } \\
\mathbf{n}(\%)\end{array}$ & $\begin{array}{l}\text { Non-surgical } \\
\mathbf{n}(\%)\end{array}$ & Total $(\mathbf{n})$ \\
\hline 1991 & $7(1.5)$ & $17(3.7)$ & 24 \\
1992 & $4(0.8)$ & $21(4.2)$ & 25 \\
1993 & $3(0.6)$ & $29(5.6)$ & 32 \\
1994 & $8(1.6)$ & $19(3.7)$ & 27 \\
1995 & $10(1.6)$ & $21(3.3)$ & 31 \\
1996 & $5(0.8)$ & $25(3.9)$ & 30 \\
1997 & $5(0.9)$ & $22(4.1)$ & 27 \\
1998 & $1(0.2)$ & $15(3.2)$ & 16 \\
1999 & $4(0.8)$ & $24(5.0)$ & 28 \\
2000 & $4(1.0)$ & $21(5.5)$ & 25 \\
Total & $51(1.0)$ & $214(4.2)$ & $265(5.2)$ \\
\hline
\end{tabular}

$\mathrm{n}$, cases of fatal pulmonary embolism; \%, percentage of necropsies undertaken. 
Table 4 Fatal pulmonary embolism associated with defined medical conditions

\begin{tabular}{lll}
\hline Medical condition & Fatal PE (n) & Fatal PE $(\%)^{*}$ \\
\hline Myocardial infarction & 3 & 2.7 \\
Cerebrovascular accident & 4 & 3.6 \\
Chronic obstructive pulmonary disease & 8 & 7.3 \\
Heart failure & 13 & 11.8 \\
Cancer & 24 & 20.9 \\
Infection & 26 & 23.6 \\
Other condition & 33 & 30.0 \\
All defined medical conditions & 110 & 100 \\
\hline
\end{tabular}

*Percentage of defined medical conditions.

$\mathrm{PE}$, pulmonary embolism.

necropsy, fatal PE was found more often in non-surgical patients than in surgical patients. Previous retrospective postmortem studies have described similar findings in medical patients. ${ }^{10}{ }^{11}$ Of the $10 \%$ of deaths in hospital as a result of PE, Sandler and Martin showed that about three quarters of these occurred in patients who had not undergone a surgical procedure linked to their last illness. ${ }^{11}$

Acute infection was the most common medical illness found in patients who had died from PE, in particular patients with respiratory infection. In a postmortem study of non-surgical patients dying in the infectious diseases department of a Swedish hospital, high numbers of patients with respiratory tract infections were also found to have died from fatal PE. ${ }^{12}$ The pathophysiology of VTE in the presence of acute infection remains to be fully defined, but recent evidence suggests that respiratory viruses are capable of infecting endothelial cells and causing a shift from anticoagulant to procoagulant activity that is associated with induction of tissue factor expression. ${ }^{13}$

The association between cancer and thrombosis is well characterised and was described more than a century ago. ${ }^{14}$ Our results appear to support Trousseau's original observations, with about one in four patients who had necropsy confirmed fatal PE suffering from cancer. These findings are in keeping with a recent clinical trial undertaken in a broad range of surgical patients, ${ }^{15}$ which used necropsy confirmed fatal $\mathrm{PE}$ as the primary study endpoint. An additional analysis of the primary trial findings revealed that PE was responsible for almost four times the number of deaths in patients undergoing cancer surgery compared with those undergoing comparable surgical procedures without cancer. ${ }^{16}$

Increased age closely mirrored increases in the numbers of fatal PE in our study. There were no cases of fatal PE in patients under age 18 years. Fatal PE was not common in the $3 \mathrm{rd}, 4 \mathrm{rth}$, or 5 th decades, but greatly increased during the 6th to 9 th decades, peaking in the 9th decade. Age is accepted as an independent risk factor for VTE. The risk of thrombosis increases greatly with age, from approximately 1/10 000 people each year before the age of 40 , to $1 / 100$ each year for those aged 75 years and over. ${ }^{17}$ It has been suggested that the association between age and VTE relates to a combination of decreased mobility and muscle tone with increased morbidity and degenerative vascular changes. ${ }^{17}$

\section{"Our study shows that pulmonary embolism is a cause of a substantial number of deaths in hospital patients, despite advances in the diagnosis and treatment of venous thromboembolic disease"}

Only three patients died of PE after MI during the 10 year study period presented here. This is in contrast to a previous study for the period 1972 to 1978 in which $31 \%$ of patients with necropsy verified fatal PE had suffered a recent MI. ${ }^{18}$
Take home messages

- Thromboembolic events are still a relatively common cause of death in hospitalised patients, despite advances in the diagnosis and treatment of venous thromboembolic disease, and appear to occur more frequently in non-surgical than in surgical patients

- Those patients who are acutely ill, especially with an acute infectious disease or active cancer, are an obvious group to identify and target with appropriate thromboprophylaxis

The low levels of fatal PE found in our study after MI probably reflect improvements in cardiac patient care, such as rapid mobilisation, more efficient treatment of heart failure, and the provision of some form of thrombolytic, antithrombotic, and/or antiplatelet treatment.

Necropsy and organ retention have become a contentious issue in the UK. The issue first came to public attention with the Bristol Royal Infirmary ${ }^{19}$ and Alder Hey inquiries,$^{20}$ which have resulted in the provision of strict guidelines on consent for postmortem examinations, in particular the retention of organs and tissue. ${ }^{21} 22$ It is thought that this publicity will significantly reduce the number of necropsies undertaken, ${ }^{23}$ which will limit future studies of the relation between hospitalisation, PE, and death. From a high of $71 \%$ in the period 1966 to 1970, the necropsy rate fell, particularly in the adult population, in the last three years of our study (19982000 ) to a low of $29.9 \%$. These findings mirror closely those of the National Confidential Enquiry into Perioperative Deaths (NCEPOD). The pathology advisors to NCEPOD described a fall from $41 \%$ in $1988-1989$ to $31 \%$ in 1999 2000 , and note that the number of necropsies will fall even further as a result of the organ retention issues. ${ }^{23}$ In our study, the necropsy rate in children less than 18 years of age dipped considerably in 1998-1999, but returned to a higher level $(79 \%)$ in 2000.

There are clear limitations to our study and also potential sources of error. Without denominator numbers for the surgical and medical patient groups, no interpretation is possible regarding the actual incidence of fatal PE. The lower number of cases of fatal PE in the surgical population could reflect a lower number of necropsies performed in deaths associated with surgical intervention. The necropsy rate was falling significantly towards the end of the 10 year study period, and this limits the strength of the conclusions that can be drawn. Because our study is retrospective it was not possible to use a uniform classification of PE. It is difficult to distinguish between fatal, contributory, and incidental emboli when the definitions and interpretations are based on pathologists' opinions across a long time period (35 years). In an attempt to minimise the number of false positives included in our analysis, only postmortem examinations describing emboli in the main pulmonary trunk or proximal pulmonary arteries as the main cause of death are included.

Our study shows that PE is a cause of a substantial number of deaths in hospital patients, despite advances in the diagnosis and treatment of VTE. We would suggest that a fatal $\mathrm{PE}$ rate of $5 \%$ in adult hospital patients is unacceptably high, given the potential to prevent and treat VTE. Those patients who are acutely ill, especially with an acute infectious disease or active cancer, are an obvious group to identify and target with appropriate thromboprophylaxis, as recommended by international, national, and local guidelines. This is not happening in our hospital ${ }^{24}$ or other 
institutions, ${ }^{25} 26$ but would have an impact on these potentially preventable deaths.

\section{Authors' affiliations}

R Alikhan, Department of Medicine, Royal United Hospital, Combe Park, Bath BA1 3NG, UK

F Peters, R Wilmott, A T Cohen, Academic Department of Surgery, Guy's, King's, and St Thomas's School of Medicine, Bessemer Road, London SE5 9PJ, UK

\section{REFERENCES}

1 Geerts WH, Heit JA, Clagett GP, et al. Prevention of venous thromboembolism. Chest 2001; 119:132S-75S.

2 Nicolaides AN, Breddin HK, Fareed J, et al. Prevention of venous thromboembolism. International consensus statement. Guidelines compiled in accordance with the scientific evidence. Int Angiol 2001;20:1-37.

3 Kahn S, Ginsberg J. The post-thrombotic syndrome: current knowledge, controversies, and directions for future research. Blood Rev 2002; 16:155

4 Heit JA, Melton $\amalg$, III, Lohse CM, et al. Incidence of venous thromboembolism in hospitalized patients vs. community residents. Mayo Clin Proc 2001;76:1102-10.

5 Heit JA, O'Fallon WM, Petterson TM, et al. Relative impact of risk factors for deep vein thrombosis and pulmonary embolism: a population-based study. Arch Intern Med 2002; 162:1245-8.

6 Hampton KK. Thromboprophylaxis in medical patients. Hosp Med 2000;61:656-9

7 Samama MM, Cohen AT, Darmon JY, et al. A comparison of enoxaparin with placebo for the prevention of venous thromboembolism in acutely ill medical patients. Prophylaxis in medical patients with enoxaparin study group. N Engl J Med 1999;341:793-800.

8 Lindblad B, Sternby NH, Bergqvist D. Incidence of venous thromboembolism verified by necropsy over 30 years. BMJ 1991;302:709-11.

9 Cohen AT, Edmondson RA, Phillips MJ, et al. The changing pattern of venous thromboembolic disease. Haemostasis 1996;26:65-71.

10 Baglin TP, White K, Charles A. Fatal pulmonary embolism in hospitalised medical patients. J Clin Pathol 1997:50:609-10.
11 Sandler DA, Martin JF. Autopsy proven pulmonary embolism in hospital patients: are we detecting enough deep vein thrombosis? J R Soc Med 1989;82:203-5.

12 Gardlund B. Fatal pulmonary embolism in hospitalized non-surgical patients. Acta Med Scand 1985;218:417-21.

13 Visseren FL, Bouwman JJ, Bouter KP, et al. Procoagulant activity of endothelial cells after infection with respiratory viruses. Thromb Haemost 2000;84:319-24

14 Trousseau A. Phlegmasia alba dolens. In: Clinique medicale de l'Hotel-Dieu de Paris, 2nd ed. Paris: JB Balliere et Fils, 1865:654-712.

15 Haas SK, Wolf $\mathrm{H}$, Encke A, et al. Prevention of fatal postoperative pulmonary embolism by low molecular weight heparin-a double blind comparison of certoparin and unfractionated heparin [abstract]. Thromb Haemost 1999;82:1548.

16 Haas S, Kakkar A, Fareed J, et al. Prevention of fatal pulmonary embolism and death in elective cancer surgery patients: a substudy comparison of certoparin with unfractionated heparin [abstract]. Blood 2000;96:4039.

17 Rosendaal FR. Venous thrombosis: a multicausal disease. Lancet 1999:353:1167-73.

18 Nielsen HK, Bechgaard P, Nielsen PF, et al. 178 fatal cases of pulmonary embolism in a medical department. Acta Med Scand 1981;209:351-5.

19 Bristol Royal Infirmary Inquiry. Learning from Bristol: the report of the public inquiry into children's heart surgery at the Bristol Royal Infirmary 1984-1995, 2001 [www.bristol-inquiry.org.uk].

20 Department of Health. The Royal Liverpool Children's inquiry: summary and recommendations, 2001 [www.rlcinquiry.org.uk].

21 Royal College of Pathologists. Guidelines on autopsy practice. Report of a working group of the Royal College of Pathologists. London: Royal College of Pathologists, 2002.

22 Chief Medical Officer, Department of Health. The removal, retention and use of human organs and tissue following postmortem examination: advice from the chief medical officer, 2001 [www.doh.gov.uk/organretention]

23 Carr NJ, Burke MM, Corbishley CM, et al. The autopsy: lessons from the national confidential enquiry into perioperative deaths. $J R$ Soc Med 2002;95:328-30

24 Alikhan R. Use of thromboprophylaxis in nonsurgical patients: survey of a London teaching hospital [abstract]. Blood 2001;98:1142.

25 Ageno W, Squizzato A, Ambrosini F, et al. Thrombosis prophylaxis in medical patients: a retrospective review of clinical practice patterns. Haematologica 2002;87:746-50.

26 Mismetti P, Laporte S. Thromboprophylaxis in acute medical patients: need for an implementation strategy. Haematologica 2002;87:673-5. 